UDC 1(100)(091)

Submitted: 27.06.2019

LBC 87.3(0)44

Accepted: 15.10 .2019

\title{
TWO NOTES ON THE NOTION OF EDUCATION BY THEODORE METOCHITES AND IN THE PATRISTIC TRADITION OF THE MIDDLE BYZANTINE PERIOD
}

\author{
Dmitriy I. Makarov \\ Urals State Mussorgsky Conservatoire, Yekaterinburg, Russian Federation
}

\begin{abstract}
Introduction. John Polemis thought that in On Education the notions of logos, paideia and theoria were synonymous. Meanwhile, Igor P. Medvedev stressed in his trail-blazing book the variety of meanings of theoria in the Late Byzantine period. Relying upon his ideas and evidence, we would like to underline, in our turn, Metochites' diversification of meanings of this notion. As a skillful conductor or musician, he was able to tune into different waves when speaking about mundane or ecclesiastical affairs. In a number of points, he diverged from traditional Orthodoxy. Methods. Using the traditional set of historical, philosophical, and hermeneutic methods, as well as those of comparative religious and cultural studies, we try to single out and analyze in some detail different layers of meaning in the treatise under discussion. If our author had made digressions into theological knowledge, it does not mean that he would have given himself completely to theology alone, as the basic line of his reasoning remained philosophical and mundane. As compared to what his fellow-Churchmen, like Callistos I, wrote on the issue of education, Metochites' ideas turn to be a rather clear-cut continuation of the ancient paideia and not especially spiritual knowledge derived from the Christian Revelation. Analysis. Thus, in his cosmological deliberations Metochites ran a risk to turn the world-creating power of God into something temporary and liable to change. He certainly did not learn well the lessons of the patristic tradition represented, e.g., by Ps.-Maximos' Chapters Full of Knowledge dating back to the $7^{\text {th }}-8^{\text {th }}$ centuries. This led to the fact that he had not recognized the operations of divine world-ordering energy in the created universe, and thus had confirmed the old assumption of H.-G. Beck that Metochites were unfamiliar with Ps.-Maximos the Confessor. At the same time, some Theodore's ideas come close to those uttered by Ps.-Maximos. Both authors criticize indeed the notion of a pure and self-contained contemplation (which expresses the negative meaning of theoria) unattached to a person's struggle with passions and vices. Even more intriguing is their common use of a widespread patristic concept of "cultivating the land of one's mind" (or: "heart"). Given the fact of Metochites' pronounced admiration of Orthodox monasticism (see, e.g., Ch. 13 of On Education), this parallel may not be incidental. It seems to be traceable to the common Biblical and ancient roots of the Byzantine spiritual culture. Results. If it is difficult to unambiguously resolve the issue of Ps.-Maximos' or Metochites' influence exerted to his counterpart, it is not to say, however, that there was not a high degree of cohesion and integrity within the philosophical and theological synthesis of the middle- and late Byzantine patristic tradition and spiritual culture in general. It is within this framework that a scholar should analyze Metochites' ideas as expressed in On Education and elsewhere.
\end{abstract}

Key words: Theodore Metochites, Ps.-Maximos the Confessor, St. Callistus I of Constantinople, treatise "On education", "Chapters filled with knowledge", contemplation, knowledge of God, epistemology, "cultivation of the land of reason".

Citation. Makarov D.I. Two Notes on the Notion of Education by Theodore Metochites and in the Patristic Tradition of the Middle Byzantine Period. Vestnik Volgogradskogo gosudarstvennogo universiteta. Seriya 4. Istoriya. ऽ. Regionovedenie. Mezhdunarodnye otnosheniya [Science Journal of Volgograd State University. History. Area Studies. International Relations], 2019, vol. 24, no. 6, pp. 297-304. (in Russian). DOI: https://doi.org/10.15688/jvolsu4.2019.6.23 


\title{
ДВЕ ЗАМЕТКИ О ПОНЯТИИ ОБРАЗОВАННОСТИ У ФЕОДОРА МЕТОХИТА И В СРЕДНЕВИЗАНТИЙСКОЙ СВЯТООТЕЧЕСКОЙ ТРАДИЦИИ
}

\author{
Дмитрий Игоревич Макаров \\ Уральская государственная консерватория им. М.П. Мусоргского, г. Екатеринбург, Российская Федерация
}

Аннотация. В 10-м слове «О нравственных проблемах, или Об образованности» (ок. 1305) Феодор Метохит говорит о созерцании как в светском (философско-гносеологическом), так и в духовном (подчеркивая значимость богопознания) смыслах. При этом общий тон трактата остается все же светским: автор выказывает знакомство с аскетикой, но ее идеи не являются определяющими для его мысли. Тем не менее существует ряд перекличек между трактатом Метохита и произведениями средневизантийской богословской традиции, например, «Главами, исполненными ведения» пс.-Максима Исповедника (CPG, 7707.11). Так, оба автора критикуют бесплодное, оторванное от практики, созерцание и пользуются сходным образом «возделывания земли рассудка». Ценность трактата Метохита уже в том, что, глубоко проанализировав пайдейю, он отделяет ее положительные и культуросозидающие, подлинно смыслостроительные аспекты от излишних и вступающих в конфликт с христианской догмой.

Ключевые слова: Феодор Метохит, пс.-Максим Исповедник, св. Каллист I Константинопольский, трактат «Об образованности», «Главы, исполненные ведения», созерцание, богопознание, гносеология, «возделывание земли рассудка».

Цитирование. Макаров Д. И. Две заметки о понятии образованности у Феодора Метохита и в средневизантийской святоотеческой традиции // Вестник Волгоградского государственного университета. Серия 4, История. Регионоведение. Международные отношения. - 2019. - T. 24, № 6. - С. 297-304. - DOI: https:// doi.org/10.15688/jvolsu4.2019.6.23

Чем более мы проникаем в средние века, тем яснее становится их близость философским стремлениям современного человека.

Вяч. Вс. Иванов [1, с. 636]

...Византийский человек позднего Средневековья более близок нам, чем его современник с Запада.

$$
\text { Поль Лемерль [2, с. 452] }
$$

Введение. Уже само заглавие Десятого слова Феодора Метохита (ок. 1270-1332) «Слово о нравственных проблемах, или Об образованности ( $\pi \varepsilon \rho і ~ \pi \alpha \imath \delta \varepsilon i ́ \alpha \varsigma) »$ вызывает вопросы у византинистов. Так, Я. Полемис считает, что в трактате понятия «логосы» (во всем многообразии значений), «образованность» (пайдейя) и «созерцание» $(\theta \varepsilon \omega \rho i ́ \alpha)$ тождественны по смыслу [17, б. 18*-19*]. Между тем нам уже доводилось писать о двух принципиально различных значениях понятия «созерцание» в трактате [3, с. 35-37], что позволяет усомниться в безоговорочности мнения греческого издателя и патролога. Нам бы хотелось углубить наблюдение И.П. Медведева о более дифференцированном использо- вании понятия «созерцание» в поздневизантийскую эпоху [5, с. 118-119] и показать, что все три выделенных Я. Полемисом понятия могли употребляться в разных смыслах, а Метохит - подобно опытному музыканту - играл то в одних «стилях» и «тональностях», то в других (действительно, порой прославляя монашество, как в гл. $13^{1}$, а порой - чисто светский интеллектуальный otium), в опыте своей мысли переходя духовно-интеллектуальную границу между исихастами и светскими гуманистами то в одном, то в другом направлении, но все же видя себя, бесспорно, по светскую и интеллектуально-философскую сторону этой границы. При этом в одних вопросах (скажем, в определении личности в той же гл. 13) он усвоил себе вполне церковную (и философскую - как, скажем, у Шеллинга) точку зрения $^{2}$, а в других - весьма заметно отклоняется от Православия ${ }^{3}$.

Анализ.

1. Ведение светское и духовное: Метохит и святоотеческая традиция (кметодологии анализа взаимоотношений). Итак, обратимся к анализу понятия образо- 
ванности в контексте сопоставления воззрений Великого логофета с представителями средне- и поздневизантийской святоотеческой традиции.

В целом представляется справедливым утверждение о том, что образованность (или ученость), вынесенная в заголовок трактата, это та самая пайдейя, в следовании которой богословы-исихасты будут обвинять своих противников в середине и второй половине XIV в., как это сделает, например, св. патриapx Каллист I Константинопольский (1350$1354,1355-1363)$, ученик св. Григория Синаита (ок. 1275-1346): «Григора же, обозревая то, что в природе, с помощью эллинской учено-

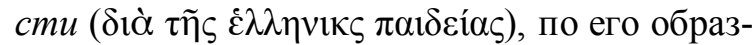
цу воображает себе и то, что превосходит природу» (курсив наш. - Д. М.) [11, p. $183.83-$ $84]^{4}$. Ценность трактата Метохита - уже в том, что, глубоко проанализировав пайдейю, он отделяет ее положительные и культуросозидающие, подлинно смыслостроительные аспекты от излишних и вступающих в конфликт с христианской догмой.

В связи с этим вместо того, чтобы бранить Метохита за секуляризм его мысли, можно подумать о другом. Например, о том, что он как раз старался четко следовать правилу, которое среди многих других Отцов Церкви сформулировал, например, в начале V в. Ceвириан Гавальский: «Пусть ни единый чело-

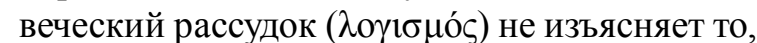
что имеет отношение к Богу. Никто не может узнать Истину иначе, как только узнавая Ее от Нее Самой» [9, p. 489.4-6].

Именно к такому «умному и вечному

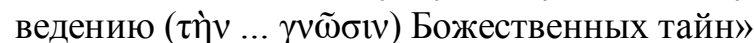
стремились Отцы и учителя Церкви - например, пс.-Максим Исповедник (VII в.) [12, p. 37.36.9-10]. При этом логос научного познания (в отличие от мистического) символически изображался фигурой Аарона, а не Моисея, то есть научной мысли придавался более подчиненный статус по отношению к духовному созерцанию и тайновидению [12, p. 42.46.1-2]. Человеческое познание ограничивается тем, что временно, тогда как знание Божественного и вечного дарует лишь Господь Иисус Христос (гл. 48: [12, р. 42.48.343.48.10]). Ведь именно Христос - «Единственная и истинная Премудрость» (гл. 72: [12, p. 55.72.2-3]; ср. 1 Кор. 1, 24). Роса знания

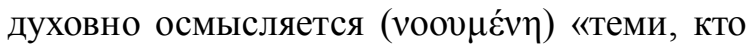
очистился духом» (гл. 60: [12, p. 48.60.8-9]; ср. гл. 93 (специально о «естественном созерцании»): [12, р. 68.93.8-11]); и т. д. Все эти положения, органичные для святоотеческой традиции, направлены на принципиальное размежевание познания мирского - рационального и эмпирического - и духовно-богословского (опытного, интуитивного и благодатно-христоцентричного) ${ }^{5}$, и Метохит, со своей стороны (как верно отмечалось И.П. Медведевым) стремился не переступать эту границу. Таковы тональность и общее настроение трактата «Об образованности».

На долю светского рассудка и выпадают другие проблемы - космологического, социологического, нравственного, исторического, одним словом, временного характера... Они и определяли собой круг гуманистических штудий в Византии, Италии, Германии, Франции. Мысля в том же русле, Метохит, думается, мог бы взять себе девизом лозунг Каталонской библиотеки в Барселоне, сформулированный в начале XX в. как «El mundo está gobernado por los libros», то есть «Миром правят книги» (цит. по: [10, р. 378] ${ }^{6}$.

Тому имеется немало доказательств в том числе и сам метод работы автора с его пристрастием к цитатности, строчкам из Гомера и Гесиода [4], а то и созданию «лоскутного ковра» из аллюзий и подтекстов. Так, в своем прославлении наук и образования Метохит следует не только византийской, но и древнеримской традиции. Ведь, например, и царь Тарквиний Древний (616-578 до н. э.) вкупе со своей женой Танаквиль своего пасынка Сервия Туллия, будущего царя, «....наставляли в науках (artibus), которые побуждают души (ingenia, досл. «способности») к служенью великому будущему (magnae fortunae)» (Tit. Liv. Hist. Rom. I, 39, 4; pyc. пер. В.М. Смирина цит. по: [6, с. 45]) ${ }^{7}$. Для царедворца Метохита все это служило актуальным напоминанием о высоте его собственного призвания. Мы уже не говорим о близости римской идеи Фортуны ряду рассуждений Метохита.

И все же вернемся к главному, к предельной цели познания - Бог или светское знание? Еще раз проиллюстрируем эту оппозицию тек- 


\section{ВИЗАНТИЙСКОЕ ПРАВОСЛАВИЕ}

стами Метохита и пс.-Максима Исповедника. В гл. 26 своего Слова Метохит подчеркивает абсолютный приоритет того научно-философского наслаждения, о котором он ведет речь: «Ибо, как я и говорил, в нашем случае наслаждение исключительно велико. Мало того, оно - прекраснейшее и незамутненное, да и связано исключительно с божественнейшей частью нашей природы, то есть только с самой душой, и притом так прочно, что вряд ли что-либо другое способно превзойти эту силу сочетания» [15, б. 126.21-24].

Платонический мотив божественности души как таковой, столь удачно раскрытый Фуко в «Алкивиаде I» и последующей традиции, сочетается здесь с мыслью о натуральности и автономности человеческого познания, не требующего для своего осуществления благодатного содействия свыше. Теперь прислушаемся к 17-й из «Глав, исполненных ведения» пс.-Максима:

«Бог, привлекая к Себе влечение алчущего, несравнимо выше всяческих, так что и не допускает алчущему устремлять (досл. «вперять», «пригвождать». - Д. М.) влечение к чему-либо из следующего за Ним» $[12$, p. 26.17.2-5].

При этом сам анонимный монах, укрывшийся за этим условным псевдонимом, называет аскезу «исполненным ведения любомуд-

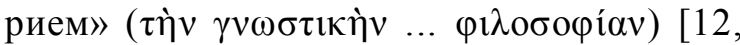
p. 29.23.3-4]. Говоря в бердяевских терминах, перед нами встает архетипичная оппозиция: творчество или аскеза? Вот вопрос, стоявший перед светским течением антикизирующего гуманизма. Да, обе стороны признают ценность любомудрия. Но понимается оно при этом весьма и весьма различно.

И если св. Григорий Палама в «Ста пятидесяти главах» делал «заход» в светскую астрономию и метеорологию, то и Метохит, со своей стороны, делал «заходы» в догматику и аскетику. Но это не значит, что он отдавал данным сферам всего себя.

2. Еще раз о богословских воззрениях Метохита в 6-й главе. Вспомним начало догматического фрагмента 6-й главы тракта-

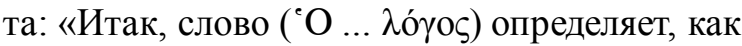
нам нужно думать: прежде всего подобает стяжать благочестивые и истинные убежде-

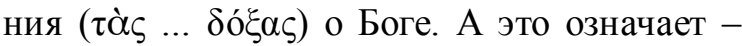

пребывать исключительно в неизреченной и несомненной вере в Троическое Богоначалие и истинное Благо...» $[15, \sigma .24 .13-16]$.

Сам по себе зачин «богословского раздела» - совершенно верный. Ср. у пс.-Максима Исповедника: «Ведь тот, кто прежде не уверует, что Бог вообще есть, ни за что не поверит и в то, что Он вочеловечился нас ради. Ибо Домостроительству нашего спасения предшествует истинное богословие» (гл. 53: [12, p. 44.53.6-9]).

Однако в учении о творении мира и в связанном с этим вопросе о соотношении вечности и времени Метохит все же был не прав. Вспомним его слова: «Эта природа (Божественная. - Д. М.) привела в движение все,

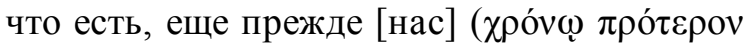
кıvท́ $\sigma \alpha \sigma \alpha) \ldots »[15, \sigma .26 .1-4]$. Похоже, что Метохит делает мирозиждительную силу Божию тварной, ибо в этой фразе он довольно явно признает ее временный характер. А ведь, по словам пс.-Максима Исповедника («Главы, исполненные ведения», гл. 6), «...очевидно, что прежде происхождения того, бытие чего не беспредельно, мыслится век или время. Но ясно, что то, прежде чего мыслится век или время, возникает из небытия» [12, p. 17.2.4-7].

Более точное с православной позиции учение об этом предмете см. в том же трактате (гл. 8): «В самом деле, если уж земные ремесла получают форму того, что производится ими, а всеобщую природу оформляют те виды, что заключены в ней, кольми же паче Бог произвел из ничего сущности всего сущего - как Сверхсущностный и, более того, беспредельно Превознесенный даже над утверждением Своей Сверхсущностности ведь это Он сочетал с ремеслами и практические навыки для изобретения форм, природе же придал энергию созидания видов и само бытие сущностей утвердил таким, каково оно есть» (курсив наш. - Д. М.) $\left[12\right.$, p. 20.7-14] ${ }^{8}$. Мы видим, что в произведении, принадлежащем к центральному руслу средне- и поздневизантийской богословской традиции, возникает мысль и о принципиальной трансцендентности Бога, и об энергийном характере проистекающих в космосе - по воле Божией процессов. Однако Метохит, по-видимому, не знал ни св. Максима Исповедника (на что 
обратил внимание еще Х.-Г. Бек [8, S. 48, Anm. 2]), ни тем более текстов из окружения преподобного.

Подобного рода факты мы и имели в виду, говоря о глубокой противоречивости отношения Метохита к традиции: и к православной, которой он и хочет следовать, но, следуя, нарушает некоторые важнейшие принципы; и к философской. Однако же приведем еще два примера того, как тот же неизвестный автор из окружения св. Исповедника, по сути, соглашается с Метохитом (как в первом случае), или же того, как оба пользуются весьма сходным образным языком (во втором случае). Речь идет, прежде всего, о выделении Феодором двух типов созерцания - активнодеятельного и пассивного [3]. Критику последнего встречаем в тех же «Главах, исполненных ведения».

С точки зрения богословия, «пассивное созерцание» также бесплодно, ибо на созерцании должно быть основано ведение. См. мысль пс.-Максима Исповедника: «...не подобает ни практическую добродетель лииать ведения, основанного на созериании

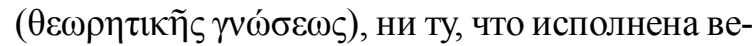
дения, достигаемого на практике умерщвления [страстей]» (курсив наш. - Д. М.) (гл. 55: $[12$, p. 45.55.10-11]). Здесь Метохит сближается и с основным течением византийской аскетической мысли.

Сближается он с пс.-Максимом и кое в чем другом. Ученые мужи, пишет Феодор в 46-й главе, «...и в теперешних условиях... занимаются научной деятельностью, посвящая ей какую-то часть себя самих, не совсем невозделанную, и не оставляют без обработки обучением (ن்⿰о̀ $\pi \alpha 1 \delta \varepsilon v ́ \sigma \varepsilon \omega \varsigma)$ землю своего рассудка...» (курсив наш. -Д. М.) [15, б. 190.3-6].

Имело бы смысл сопоставить этот образ с традиционным монашеским образом «земли сердца» в «Духовных беседах» пс.Макария Египетского, «Методе священной молитвы и внимания» и т. п. Пока неясно, что перед нами: сходство архетипов, сформировавшихся параллельно и независимо друг от друга в разных культурных традициях Византии, или нечто большее. Подобного рода выражения - не редкость в памятниках византийской аскетической письменности. Ср. в «Главах, исполненных ведения» пс.-Максима
Исповедника (гл. 99): «Ибо не подобает обучающимся приносить Богу слово ( невозделанное - но такое, которое уже было бы обработано достодолжным земледелием

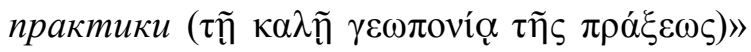
[12, p. 71.99.9-12].

Выводы. Сегодня, когда важно говорить вслед за Платоном о параллелях между душой и космосом или подчеркивать роль слова в формировании духовной культуры славян и народов иных языковых групп, не менее значимо не упускать из виду тот удивительный центр средневековой европейской и мировой культуры, который не до конца постижимым образом сводил в своей деятельности воедино все эти смыслы - византийскую философию, богословие, правовую, лингвистическую и эстетическую мысль. Идейно-образные, языковые и смысловые пересечения между разными гранями этого «магического кристалла» бесконечно глубоки и поучительны для нас. Феодор Метохит и представители средне- и поздневизантийской аскетической традиции (таковыми для нас послужили, прежде всего, пс.-Максим Исповедник и св. патриарх Каллист I) - лишь один из многих исторически сложившихся тому примеров.

Следует обратить внимание на противоречивость отношения Метохита к православной традиции (в этом плане его поучительно будет сопоставить с Пселлом). Совершая нередкие «заходы» на территорию православного богословия и догматики, Метохит в ряде случаев отклоняется от православной традиции. Это особенно видно в 6-й главе трактата, где идет речь, по сути, о тварности мирозиждительной силы Божией (вопреки четким указаниям пс.-Максима Исповедника на сей счет). С другой стороны, критика пассивной формы созерцания и учение о возделывании земли рассудка сближают нашего гуманиста с данным представителем средневизантийской святоотеческой традиции. Подобного рода колебания свободной по сути, но внутренне еще во многом определяющейся христианской традицией философской мысли характерны для гуманистов антикизирующего типа, к каковым мы в первую очередь и можем отнести Феодора Метохита и его ученика Никифора Григору. 


\section{ПРИМЕЧАНИЯ}

${ }^{1}$ «Поистине, эти люди настолько презрели все видимое, что избрали для себя сроком на всю жизнь отдаление от всего, чем живет этот мир, сделавшись горячими и непреклонными приверженцами одного лишь Прекрасного и при помощи лучшего помысла ( от убийства, крови и грохота битв» $[15, \sigma .60 .13-18]$.

2 «Возвышенные, - пишет Метохит, - они достигли высот и одолели саму природу» $[15$, б. 60.18 19]. В этом преодолении природы и заключается определение личности (например, по В.Н. Лосскому), восходящее к важнейшему в христианстве догматическому различию между природой и ипостасью. Напротив, если вспомнить Шеллинга: «Только существо, лишенное свободы, могло покориться судьбе (Nur ein Wesen, das der Freiheit beraubt war, konnte dem Schicksal unterliegen)» [7, c. $149 ; 13$, S. 232].

${ }^{3}$ К статье Д.И. Макарова мы чуть далее также сделаем несколько дополнений [4].

${ }^{4}$ Ср.: [11, p. 184.110-112], где осуждается превратное мнение о душе Платона и Пифагора.

${ }^{5} \mathrm{Cp}$. в целом характерное заявление современного греческого византиниста, подчеркивающего гармоничность сосуществования в Византии античной и христианской традиций: «Основным фактором самосознания для представителей византийской цивилизации являлась греческая образованность» $[16$, б. 226].

${ }^{6}$ К этому изречению допустим ряд параллелей скажем, из Нобелевской речи Иосифа Бродского.

${ }^{7}$ Русский перевод этого места несколько амбивалентен в передаче главного термина; ср.: ...puerum liberum loco coeptum haberi erudirique artibus quibus ingenia ad magnae fortunae cultum excitantur (латинский текст цит. по: [14]).

${ }^{8}$ О непостижимости Божией ср.: «...ибо Бог, будучи сверхсущностным и, более того, беспредельно превознесенным надо всякой сверхсущностностью, пожелав ограничить Себя сущностью (досл. «прийти в сущность», но собственно - «стать сущностью». - Д. М.), осуществовался сверхсущностным образом») [12, p. 24.14.6-9].

\section{СПИСОК ЛИТЕРАТУРЫ}

1. Иванов, В. В. Очерки по предыстории и истории семиотики / В. В. Иванов // Избранные труды по семиотике и истории культуры. Т. 1. Знаковые системы, кино, поэтика. - М. : Языки русской культуры, 1999. - С. 605-791.

2. Лемерль, П. Первый византийский гуманизм. Замечания и заметки об образовании и культуре в
Византии от начала до Х века / П. Лемерль ; пер. с фр. Т. А. Сениной (монахини Кассии). - СПб. : Свое издво, 2012. - XIV, 490 c.

3. Макаров, Д. И. Феодор Метохит о двух видах созерцания / Д. И. Макаров // Византийский мир: реалии и интерпретации : тез. докл. XIV науч. Сюзюмовских чтений (Екатеринбург, 10-12 октября 2018 г.) / под ред. Т. В. Кущ. - Екатеринбург : Издво Уральского ун-та, 2018. - С. 35-37.

4. Макаров, Д. И. «Присно блажен тот, кого возлюбили Музы». Феодор Метохит между античной пайдейей и христианской молитвой (на материале 10 слова «Об образованности») / Д. И. Макаров // Юбилейный сборник в честь 80-летия митр. Черногорско-Приморского Амфилохия (Радовича) и еп. Призренского Афанасия (Йевтича) / под ред. М. Кнежевича. - Косовска Митровица, 2019. (В печати).

5. Медведев, И. П. Византийский гуманизм XIV-XV вв. / И. П. Медведев. -СПб. : Алетейя, 1997. $336 \mathrm{c}$.

6. Тит Ливий. История Рима от основания города. Т. 1. Книги I-X / пер. В. М. Смирина ; отв. ред. Е. С. Голубцова. - М. : Наука, 1989. - 576 с. (Памятники исторической мысли).

7. Шеллинг, Ф. В. Й. Философскиеписьма о догматизме и критицизме. Десятое письмо / Ф. В. Й. Шеллинг // Ранние философские сочинения / пер. с нем., вступ. ст., коммент., примеч. И. Фокина. - СПб. : Алетейя, 2000.-С. 148-152.

8. Beck, H.-G. Theodoros Metochites. Die Krise des byzantinischen Weltbildes im 14. Jahrhundert / H.-G. Beck. - München : C.H. Beck, 1952. - 156 S.

9. Kim, S. Severiano di Gabala : Un nuovo frammento greco / S. Kim // Orientalia Christiana Periodica. - 2017. - Vol. 83/2. - P. 485-490.

10. Meinhardt Teixidor, T. Revisió de : Comparatistes sense comparatisme. La literatura comparada a Catalunya / T. Meinhardt Teixidor // Tropelías. Revista de Teoría de la Literatura y Literatura Comparada. - 2018. - Vol. 30. - P. 377-381.

11. Paidas, C. An Unedited Discourse On the Ignorance of the Holy Scriptures by the Patriarch Kallistos I / C. Paidas // "Pour une poétique de Byzance". Hommage à Vassilis Katsaros / ed. S. Efthymiadis [et al.]. - Paris : [s. n.], 2015. - P. 177-186. - (Dossiers byzantins; vol. 16).

12. Ps.-Maximi Confessoris, Capita gnostica ( $C P G$ 7707.11) // Maximi Confessoris Capita de duabus Christi naturis necnon Pseudo-Maximi Confesssoris Capita gnostica / ed. K. Levrie. - Turnhout : Brepols, 2017. - P. 17-72. - (Corpus Christianorum. Series Graeca ; vol. 89).

13. Schelling, F. W. J. Philosophische Briefe über Dogmatismus und Kriticismus / F. W. J. Schelling // Philosophisches Journal einer Gesellschaft Teutscher Gelehrten. - 1795. - Bd. 3, Hf. 3. - S. 231-239. - 
Electronic text data. - Mode of access: https://www.unidue.de/lyriktheorie/texte/1795_schelling.html\#edition) (date of access: 18.05.2019). - Title from screen.

14. Titus Livius. Historia Romae ab urbe condita / Titus Livius. - Electronic text data. - Mode of access: https://latin.packhum.org/loc/914/1/0\#39 (date of access: 10.05 .2019$)$. - Title from screen.

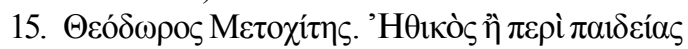

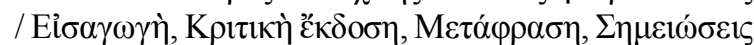

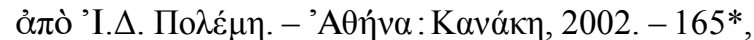

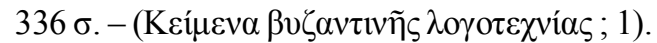

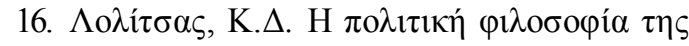

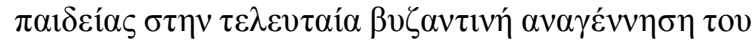

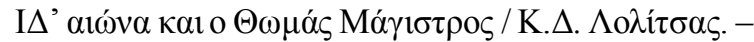

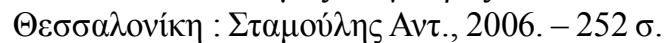

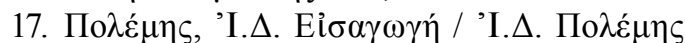

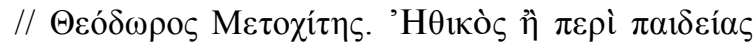

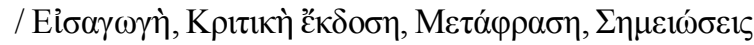

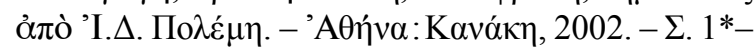

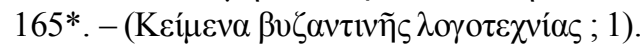

\section{REFERENCES}

1. Ivanov V.V. Ocherki po predystorii i istorii semiotiki [Essays on the Background and History of Semiotics]. Ivanov V.V. Izbrannye trudy po semiotike i istorii kultury. T. 1. Znakovye sistemy, kino, poetika [Selected Works on Semiotics and Cultural History. Vol. 1. Sign Systems, Cinema, Poetics]. Moscow, Yazyki russkoy kultury Publ., 1999, pp. 605-791.

2. Lemerl P. Pervyy vizantiyskiy gumanizm. Zamechaniya i zametki ob obrazovanii i kulture $v$ Vizantii ot nachala do $X$ veka [The First Byzantine Humanism. Remarks and Notes on Education and Culture in Byzantium from the Early $10^{\text {th }}$ Century]. Saint Petersburg, Svoe izdatelstvo, 2012. XIV, 490 p.

3. Makarov D.I. Feodor Metohit o dvukh vidakh sozertsaniya [Theodore Metochites on Two Types of Contemplation]. Kushch T.V., ed. Vizantiyskiy mir: realii i interpretatsii. Tezisy dokladov XIVnauchnykh Syuzyumovskikh chteniy (Ekaterinburg, 1012 oktyabrya 2018 g.). [Byzantine World: Realities and Interpretations. Abstracts of the $14^{\text {th }}$ Scientific Suzyumov Readings (Yekaterinburg, October 10-12, 2018)]. Yekaterinburg, Izd-vo Uralskogo universiteta, 2018, pp. 35-37.

4. Makarov D.I. «Prisno blazhen tot, kogo vozlyubili Muzy»». Feodor Metokhit mezhdu antichnoy paydeyey i khristianskoy molitvoy (na materiale 10 slova «Ob obrazovannosti») ["He Blessed is the One Whom the Muses Loved". Theodore Metochites Between Ancient Paideia and Christian Prayer (On the Material of the $10^{\text {th }}$ Word "On Education")]. Knezhevich M., ed. Yubileynyy sbornik v chest 80letiya mitr. Chernogorsko-Primorskogo Amfilokhia
(Radovicha) i ep. Prizrenskogo Afanasia (Yevticha) [Anniversary Collection in Honor of the $80^{\text {th }}$ Anniversary of Metropolitan Montenegrin-PrimorskyAmphilochius (Radovic) and Bishop Prizrensky Athanasius (Yevtich)]. Kosovska Mitrovica, 2019 (in print).

5. Medvedev I.P. Vizantiyskiy gumanizm XIV$X V v v$. [Byzantine Humanism of the $14^{\text {th }}-15^{\text {th }} \mathrm{cc}$.]. Saint Petersburg, Aleteya Publ., 1997. 336 p.

6. Smirin V.M., transl.; Golubtsova E.S., ed. Tit Liviy. Istoriya Rima ot osnovaniya goroda. T. 1. Knigi $I-X$ [Titus Livius. The History of Rome from the Foundation of the City. Vol. 1. Books I-X]. Moscow, Nauka Publ., 1989. 576 p. (Pamyatniki istoricheskoy mysli [Monuments of Historical Thought]).

7. Shelling F.V.Y. Filosofskie pisma o dogmatizme i krititsizme. Desyatoe pismo [Philosophical Letters About Dogmatism and Criticism. Tenth Letter]. Fokina I., ed. Shelling F.V.J. Rannie filosofskie sochineniya [Shelling F.V.J. Early Philosophical Works]. Saint Petersburg, Aleteya Publ., 2000, pp. 148-152.

8. Beck H.-G. Theodoros Metochites. Die Krise des byzantinischen Weltbildes im 14. Jahrhundert. München, C.H. Beck, 1952. 156 p.

9. Kim S. Severiano di Gabala: un nuovo frammento Greco. Orientalia Christiana Periodica, 2017, vol. 83/2, pp. 485-490.

10. Meinhardt Teixidor T. Revisió de: Comparatistes sense comparatisme. La literatura comparada a Catalunya. Tropelías. Revista de Teoría de la Literatura y Literatura Comparada, 2018, vol. 30, pp. 377-381.

11. Paidas C. An Unedited Discourse On the Ignorance of the Holy Scriptures by the Patriarch Kallistos I. Efthymiadis S. et al., eds. "Pour une poétique de Byzance”. Hommage à Vassilis Katsaros. Paris, [s.n.], 2015, pp. 177-186. (Dossiers byzantins, vol. 16).

12. Ps.-Maximi Confessoris, Capita gnostica ( $C P G$ 7707.11). Levrie K., ed. Maximi Confessoris Capita de duabus Christi naturis necnon Pseudo-Maximi Confesssoris Capita gnostica. Turnhout, Brepols, 2017, pp. 17-72. (Corpus Christianorum. Series Graeca, vol. 89).

13. Schelling F.W.J. Philosophische Briefe über Dogmatismus und Kriticismus. Philosophisches Journal einer Gesellschaft Teutscher Gelehrten, 1795, Bd. 3, Hf. 3, S. 231-239. URL: https://www.uni-due.de/ lyriktheorie/texte/1795_schelling.html\#edition (accessed 18 May 2019).

14. Titus Livius. Historia Romae ab urbe condita. URL: https://latin.packhum.org/loc/914/1/0\#39 (accessed 10 May 2019).

15. Poleme I.D., ed. Theodoros Metochites. Ethikos e peri paideias [Theodore Metochites. A Treatise on the Ethical Problems or on Education]. Athena, Kanake, 2002. 165*, 336 p. (Keimena byzantines logotechnias, vol. 1). (in Greek). 


\section{ВИЗАНТИЙСКОЕ ПРАВОСЛАВИЕ}

16. Lolitsas K.D. He politike philosophia tes paideias sten teleutaia byzantine anagennese tou 14 aiona kai o Thomas Magistros [The Political Philosophy of Education During the Late Byzantine Renaissance of the $14^{\text {th }}$ Century and Thomas Magistros]. Thessalonike, Stamoules Ant. Publ., 2006.252 p. (in Greek).
17. Polemes I.D. Eisagoge [Introduction]. Theodoros Metochites. Ethikos e peri paideias [Theodore Metochites. A Treatise on the Ethical Problems or on Education]. Athena, Kanake Publ., 2002, pp. $7 *-165 *$. (Keimena byzantines logotechnias, vol. 1). (in Greek).

\section{Information about the Author}

Dmitriy I. Makarov, Doctor of Sciences (Philosophy), Associate Professor, Professor, Head of the Department of General Humanities, Urals State Mussorgsky Conservatoire, Prosp. Lenina, 26, 620014 Yekaterinburg, Russian Federation, dimitri.makarov@mail.ru, https://orcid.org/0000-0002-3902-6190

\section{Информация об авторе}

Дмитрий Игоревич Макаров, доктор философских наук, доцент, профессор, заведующий кафедрой общих гуманитарных дисциплин, Уральская государственная консерватория им. М.П. Мусоргского, просп. Ленина, 26, 620014 г. Екатеринбург, Российская Федерация, dimitri.makarov@mail.ru, https://orcid.org/0000-0002-3902-6190 